\title{
Cuando se quebró el muro. Algunas notas acerca de la crisis en el Partido Comunista argentino durante los años 1980
}

\author{
When the wall broke. Some notes about the crisis in the Argentine \\ Communist Party during the 1980s
}

\begin{abstract}
Natalia Casola*
Resumen: Este artículo reflexiona en torno de la crisis al interior del Partido Comunista argentino (PCA) durante la década de 1980. El objetivo es indagar en las causas que provocaron la crisis y analizar sus modos de expresión con relación a dos núcleos de problemas: 1) el debate político-programático y 2) el funcionamiento interno. A lo largo del escrito se intentará demostrar que la crisis y los fraccionamientos que sobrevinieron fueron consecuencia del llamado "viraje revolucionario", tanto por sus éxitos como por sus limitaciones.

Palabras clave: Partido Comunista argentino, XVI Congreso, viraje revolucionario, crisis

Abstract: This article reflects on the crisis within the Argentine Communist Party (PCA) during the 1980s. The objective is to investigate the causes that caused the crisis and analyze their modes of expression in relation to two core problems: 1) the political-programmatic debate and 2) the internal functioning. Throughout the writing will try to demonstrate that the crisis and the divisions that ensued were a consequence of the so-called "revolutionary turn", both for its successes and for its limitations.
\end{abstract}

Keywords: Argentine Communist Party, XVI Congress, revolutionary turn, crisis

Recibido: 10 de julio 2019 Aceptado: 25 octubre 2019

\footnotetext{
* Argentina. Doctora en Historia. Investigadora de Conicet y miembro del Instituto Interdisciplinario de Estudios de Género (IIEGE-UBA), nataliacasola@hotmail.com
} 
"La democracia, el democratismo, el verdadero, no el ficticio, queda comprendido, como la parte en el todo, en el concepto de camaradería del partido". Lenin, Obras Completas, Tomo V, Buenos Aires: Cártago, p.534.

En este artículo me propongo analizar la crisis desenvuelta al interior del Partido Comunista Argentino (PCA) durante los años 1980. El objetivo no es realizar una síntesis descriptiva de la historia partidaria en aquellos años, sino reflexionar en torno de un único pero esencial problema: las características de la crisis más honda en toda la historia de la organización, los modos en que fue procesada y sus consecuencias, es decir, los reagrupamientos y sucesivas rupturas. ${ }^{1}$

A lo largo de su historia el PCA atravesó numerosas disputas internas que invariablemente concluyeron con la separación, por renuncia o expulsión, de los grupos disidentes. ${ }^{2}$ Sin embargo, ninguna de las crisis fue tan multifacética como la de los años 1980 que se distinguió de las anteriores, entre otras cosas, por su carácter público, un elemento que profundizó su hondura y entroncó con un contexto ideológico adverso para el marxismo en general.

Este escrito, en alguna medida, actualiza y replantea cuestiones ya desarrolladas en mi libro El PC argentino y la dictadura militar, publicado en 2015. En aquel momento, mi análisis de los años 80 estaba muy influido, como no podía ser de otro modo, por lo que había reconstruido sobre el partido durante la dictadura militar. Desde luego, la línea sostenida entre finales de 1975 y 1983, la "convergencia cívico militar", constituyó una herencia problemática que jugó un papel importante tanto en la expresión del malestar interno como en la necesidad de producir una revisión profunda ${ }^{3}$. Sin embargo, creo que esa explicación debe ser puesta a jugar en paridad con otros aspectos del periodo. El elemento que más complejizaría sobre mi primera versión de la crisis partidaria es el que enfatizaba los puntos de continuidad con el programa histórico del comunismo dentro del llamado "viraje revolucionario", en especial de aquellos que supuestamente venían a producir cambios, por ejemplo, el reemplazo de la estrategia de Frente Democrático Nacional (FDN) por el Frente de Liberación Nacional y Social (FLNS). Vale recordar que, cuando escribí ese capítulo, señalar los elementos de continuidad con la línea tradicional

\footnotetext{
${ }^{1}$ De acuerdo con Perry Anderson, el estudio marxista de un partido comunista requiere de la consideración de múltiples factores: su historia política interna, la especificidad de su cultura en tanto expresión de un grupo nacional, el arraigo nacional alcanzado, además de la compleja interrelación entre los factores nacionales e internacionales. En este artículo el énfasis estará puesto en la política interna, entendida no sólo por la definición de su línea, sino también por las formas de organización y prácticas militantes. No obstante, intentaremos dar cuenta de la manera en que el resto de los factores influyeron sobre la problemática recortada. Véase, Perry Anderson, "La historia de los partidos comunistas", en Raphael Samuel (Ed.), Historia popular y teoría socialista, Barcelona, Editorial Crítica, 1984.

2 Para una reseña sintética sobre la historia del PCA, su periodización, sus momentos de crecimiento y de crisis, véase, Jorge Cernadas, Horacio Tarcus y Roberto Pittaluga, "La historiografía sobre el Partido Comunista de la Argentina: un estado de la cuestión", El Rodaballo, n 8: Buenos Aires, 1998.

${ }^{3}$ Durante toda la dictadura militar el PCA sostuvo que existía una disputa al interior de la Junta Militar entre un ala "moderada" y una "pinochetista", de carácter fascista. En esta contienda, opinaban que convenía apoyar a los primeros y fortalecer su posición con la construcción de una convergencia cívico-militar.
} 
resultaba necesario porque, tanto en la memoria oficial del partido como en los escasos trabajos académicos que hacían referencia al periodo, invariablemente se repetía que el XVI Congreso de 1986 había realizado un viraje profundo de la línea ${ }^{4}$. Entonces, mostrar los límites de esa interpretación advertía sobre la necesidad de ser más incisivos con el uso de la teoría y menos concesivos con la empírea, para pensar hasta qué punto el viraje no había sido una especie de maniobra "gatopardista" de cambiar para no cambiar nada. Casi cinco años después considero que mi trabajo permitió abrir una senda de reflexión sobre aquel período pero abrevando en una visión relativamente incompleta. En esta versión, propongo pensar la crisis como resultado del propio "viraje" en su totalidad: por sus continuidades e inconsistencias, tanto a nivel de la línea como en los modos de organización partidaria, como por los cambios y sus efectos en la subjetividad militante que alteraron de modo decisivo la relación entre la dirección y el resto de la estructura hacia la base fijando un punto de no retorno. Dicho de un modo más simple, mi hipótesis es que la crisis partidaria es fruto tanto de las limitaciones como de los éxitos del viraje.

Ahora bien, saliendo del ámbito partidario, hacia afuera, dos procesos de carácter general contribuyen a comprender por qué la crisis tuvo lugar en esa coyuntura y no antes ni después: en primer término, en los años 80 se desenvolvió la etapa final de otra crisis, la del bloque soviético y, por extensión, la del Movimiento Comunista Internacional (MCI). Con todo, antes que el desplome del mundo socialista hiciera estragos en la izquierda en todo el mundo, la URSS apostó a un "último acto" destinado a disimular la transición al capitalismo: la implementación de la glásnost y la perestroika que sirvieron para prolongar las ilusiones sobre la capacidad de regeneración del socialismo. Existe un sentido común establecido alrededor del viraje del XVI Congreso que afirma que se trató de un momento de ruptura con el mundo soviético y de vuelco hacia América Latina. Sin embargo, se trata de una verdad a medias. La revalorización de los procesos regionales, la búsqueda de originalidad política y reafirmación de la autonomía no fueron resultado de una ruptura con el mundo soviético. Por lo contrario, podría decirse que el Muro de Berlín cayó sobre la cabeza de los comunistas argentinos quienes, hasta último momento, apostaron al éxito del proceso de la "renovación" moscovita. Así, los proyectos de "democratización" por arriba del mundo soviético fueron seguidos con entusiasmo e inclusive encontraron allí fuentes de inspiración y legitimación para encarar la propia transformación ${ }^{5}$.

4 Graciela Browarnik, "Sangre roja. Un estudio acerca de la transmisión de la tradición del Partido Comunista argentino durante la última dictadura militar y la posdictadura", Testimonios, №1, Buenos Aires, 2009, pp. 2035; Isidoro Gilbert, La Fede, Buenos Aires, Sudamericana, 2009; Paula Daniela Fernández Hellmund, Nicaragua debe sobrevivir. La solidaridad de la militancia comunista argentina con la Revolución Sandinista (1979-1990), Buenos Aires, Imago Mundi, 2015. Si bien el trabajo de Hellmund da cuenta de las inconsistencias que dejó el XVI Congreso como plataforma para entender desacuerdos posteriores, no analiza en profundidad en qué consistían las ambigüedades. Otro trabajo que escapa a esta lógica es el ya referido artículo colectivo de Cernadas, Tarcus y Pittaluga (1998). Sin embargo, como su objetivo no era analizar en profundidad el periodo que nos compete dejaron los elementos presentados sin ir completamente a fondo en el balance. Dos testimonios que brindan muchos datos sobre aquella época y los vericuetos de los enfrentamientos internos son los libros de Alberto Nadra, Secretos en rojo, un militante entre dos siglos, Buenos Aires, Corregidor, 2012 y Jorge Sigal, El día que maté a mi padre, confesiones de un ex comunista, Buenos Aires, Sudamericana, 2006.

5 Algunos ejemplos son los siguientes artículos: Alexander Bovin, "La Perestroica y los destinos del socialismo", Ideología y Política, Año 1, N¹, agosto-septiembre de 1987. Bóvin era miembro del CC del PCUS; Mario José Brabivker, “Lenin sin dogmas” y Abel García Barceló, ¿Puede haber revolución en la revolución?”, 
En segundo lugar, las ilusiones propias del contexto de "transición a la democracia" operaron como telón de fondo para los planteos de redemocratización interna y lucha contra todo tipo de autoritarismo. A su modo, el PCA también participó de las expectativas que se abrieron durante la posdictadura en torno de la capacidad de la democracia para transformar el país. Durante los primeros años del gobierno de Alfonsín, el PCA participó del extendido temor a un nuevo golpe de Estado. En consecuencia, comenzaron a prepararse para evitarlo, lo que significaba nutrir y aceitar el frente militar del partido, un elemento que, para sorpresa de Alfonsín, fue comunicado como una muestra de lealtad a la democracia. Como quedó demostrado más tarde cuando ocurrieron los sucesos de La Tablada, el PCA no era el único partido que imaginaba una reconciliación entre violencia y democracia. ${ }^{6}$ Sin embargo, al promediar la década de 1980 todavía existían ilusiones sobre el alfonsinismo y su decisión para enfrentar, con el pueblo movilizado, los pronunciamientos militares 7.

En lo que sigue del artículo propongo analizar la crisis partidaria poniendo en relación dos aspectos nodales: a) el debate teórico-político acerca del programa y la línea, los puntos iniciales sobre los que parecía existir consenso y las inconsistencias posteriores que dieron lugar a múltiples interpretaciones en torno del contenido del viraje y b) la lucha de poder dentro y por el control del aparato partidario. Al respecto, consideramos muy sugerente el análisis que realiza el historiador chileno Rolando Álvarez sobre la crisis del PC de Chile durante los años 19908. En su visión, las crisis ponen en juego las trayectorias militantes y los resultados de las pugnas se relacionan con el mayor o menor capital político que detentan quienes se enfrentan en el transcurso. Si miramos la crisis del partido argentino con este marco interpretativo podemos pensar que mayor capital político no necesariamente era sinónimo de más experiencia en la organización. Por lo contrario, la longevidad fue una característica que operó en contra de la dirigencia tradicional. Rúbens Íscaro, por tomar un caso emblemático, comenzó a ser criticado por personificar un estilo de construcción estalinista considerado caduco, a pesar de haber sido

en Ideología y Política, Año 1, N³, diciembre de 1987; Esta producción fue reforzada con notas en el periódico partidario, en la revista Cuadernos de Cultura y con la circulación de folletos de propaganda soviética distribuidos en todo el mundo, en diferentes idiomas, por la editorial de la agencia de prensa soviética Nóvosti.

6 El 23 de enero de 1989, 42 integrantes del Movimiento Todos por la Patria (MTP) tomaron el Tercer Regimiento de Infantería Mecanizada General Belgrano de La Tablada. El enfrentamiento, que duró 27 horas, dejó un saldo de 43 muertos y decenas de heridos. EL MTP era dirigido por Gorriarán Merlo, ex militante del Partido Revolucionario de los Trabajadores (PRT) y había surgido en el fragor de la lucha en Nicaragua.

7 La relación con el gobierno de Alfonsín durante estos años excede los modestos propósitos de este trabajo. Sin embargo, vale la pena una futura reconstrucción acerca de la visión que tenía el gobierno en torno del "viraje" comunista. Por lo pronto, digamos que cuando quedaron conformadas las brigadas del café en apoyo a Nicaragua la sorpresa oficial fue enorme y existió una seria preocupación sobre el curso de la interna comunista. El gobierno, haciéndose eco de algunas declaraciones de militantes veteranos excluidos, realmente pensaba que el PCA podía ingresar a la lucha armada.

8 Rolando Álvarez, “¿Herejes y renegados?: la diáspora de la disidencia comunista chilena

(1989-1994)", VIII Jornadas de Trabajo en Historia Reciente, Facultad de Humanidades, Universidad Nacional de Rosario, 9 al 12 de agosto de 2016. Salvando las distancias existentes entre el arraigo nacional conseguido por el PCCh y el PCA respectivamente, tomamos de este trabajo el encuadre metodológico cuya utilidad trasciende las características nacionales de cada formación. 
por décadas símbolo del dirigente obrero abnegado, un prestigio que le había valido ser designado como candidato a presidente en 1983. Otro elemento interesante es que aun quienes, entre los dirigentes más añosos, se mantuvieron en las filas "renovadoras" lo hicieron desde lugares de menor exposición pública tanto dentro como fuera del partido. Un ejemplo es el de Fanny Edelman, que militó en las filas comunistas desde la década de 1930 y, sin embargo, participó del viraje sin profundizar en las contradicciones que establecía con su pasado. Fue "madrina" de las brigadas del café y alentó la empresa alineándola con la larga tradición de solidaridad antifascista.

En oposición, la pertenencia a una generación más joven, que había detentado en el pasado niveles de responsabilidad menores en la escala partidaria, podía ser mostrada como una credencial adecuada para aspirar al título de "renovador". Como puede verse, no se trataba sólo de una cuestión etaria, aunque la edad también jugó un papel. Más bien se trataba de qué niveles de poder y, por tanto, de responsabilidad, había tenido cada quien, frente a coyunturas sensibles, en especial, a partir de 1976. Implícita y análogamente a lo que ocurrió en el plano de la justicia transicional, también en el PCA quedaron planteados "niveles de responsabilidad" y se determinó que algunos entre quienes habían "impartido órdenes" no podían seguir al frente de la conducción partidaria. De todos modos, como quedará de manifiesto más adelante, esta cuestión fue problemática porque ninguno de los "jóvenes viejos" promotores del cambio había alzado su voz en el pasado, ni siquiera cuando en 1973 Ernesto Giúdice había escrito en solitario un largo alegato contra la burocratización del partido titulado, Carta a mis camaradas. Quizás por eso, para resolver la contradicción que suponía presentar la contienda como una oposición entre "jóvenes" y "viejos", los "renovadores" se presentaban a sí mismos como la "reserva revolucionaria" en la que podía apoyarse el conjunto del partido para "retomar" la senda revolucionaria9.

En lo que sigue de este escrito voy a realizar el siguiente recorrido: en primer lugar, haré un repaso en torno de la crisis partidaria en estos años, sus momentos, circunstancias y características haciendo hincapié en los debates políticos que introdujo el "viraje" y sus inconsistencias. Luego me voy a detener en lo que considero el núcleo de la crisis: la caducidad del modelo de dirección basado en el centralismo burocrático, al menos con relación al principio de fe ciega en la dirección, y su reemplazo por el intento de encarar la democratización interna, un proyecto que, una vez iniciado, desató tendencias centrífugas, contradictorias, que culminaron con el fraccionamiento del partido.

De acuerdo con Gramsci, "es difícil pensar que un partido político cualquiera [...] no cumpla asimismo una función de policía, vale decir, de tutela de un cierto orden político y legal". Pero esta función, inevitable en alguna medida, puede ser progresista o regresiva, democrática o burocrática, en el sentido de un centralismo burocrático: "en este segundo caso, el partido es meramente ejecutor, no deliberante"10. Más concretamente, explica:

\footnotetext{
9 "Hay que partir, en este aspecto, del reconocimiento expreso de que el viraje se impone, a pesar de la desviación oportunista, porque en el Partido, existían las reservas revolucionarias que están presentes desde su nacimiento y su historia". Folleto, "La transformación leninista del partido", junio de 1987, p.10.

10 Antonio, Gramsci, Notas sobre Maquiavelo, Buenos Aires, Nueva Visión, 1984, p.36.
} 
"la preponderancia del centralismo burocrático en el Estado [y en los partidos] indica que el grupo dirigente está saturado, que se ha transformado en una camarilla estrecha que tiende a perpetuar sus mezquinos privilegios, regulando, o también sofocando, el nacimiento de las fuerzas opositoras, aunque estas fuerzas sean análogas a los intereses dominantes fundamentales" 11 .

En este documento, intentaremos abordar la cuestión sobre la burocratización del partido a partir de este marco teórico. En cierto sentido, como veremos en breve, los renovadores también partían de supuestos parecidos. Sin embargo, los anhelos de transformación eran mayores o menores de acuerdo a los grupos que comenzaron a formarse bajo el paraguas de la renovación. En este sentido, mientras para algunos alcanzaba con cambiar la dirección del partido, para otros, comenzó a ponerse en el tapete la propia vigencia del partido tal como lo conocían hasta el momento.

\section{El viraje en su curva ascendente (1983-1986)}

A grandes rasgos, podría decirse que la crisis del PCA durante los años 1980 se procesó en dos fases: una primera que comenzó con la realización del XV Congreso en 1983 y se extendió hasta el XVI Congreso de 1986 y una segunda que se inició apenas proclamado el "viraje" y se prolongó hasta fines de la década, coincidiendo además con la realización del XVII Congreso en 199012. Que la crisis haya tenido como principales mojones las instancias congresales se explica por la propia función estatutaria asignada a esta instancia de deliberación en la que todo el partido participa, aun cuando la mayor parte de la militancia lo hace en los debates pre-congresales y, luego, a través de delegados. Pero también es una muestra de la dinámica propia de este periodo atravesado por el debate interno y la búsqueda de democratización. Entre 1946 y 1983 hubo tan solo cuatro congresos mientras que sólo en la década de 1980 se realizaron tres.

La primera etapa de la crisis, aun fiel a la tradición secretista, dejó pocas huellas en los discursos públicos y documentos de circulación interna. Aunque la sola explicitación de la necesidad de revisar la política del partido era síntoma de la existencia de desacuerdos, todavía era posible mostrar la apertura de las deliberaciones como un movimiento unitario. En la medida que el proceso de reforma interna comenzó como una iniciativa oficial, desde adentro y por "arriba", permitía mantener la ilusión sobre las posibilidades de evitar los desbordes y retener el control sobre el alcance y el contenido de los cambios. El núcleo promotor del cambio era heterogéneo en su composición, pero tuvo como eje más influyente al grupo de los "jóvenes viejos": militantes de entre treinta y

\footnotetext{
${ }^{11}$ Idem, p. 92. En oposición, para Gramsci, el centralismo democrático es "orgánico" porque toma en cuenta el movimiento y no se esteriliza.

12 En rigor, durante la década de 1990 se produjeron nuevas fracturas, entre ellas, una importante que dio origen al Partido Comunista Congreso Extraordinario en 1996. De todos modos, considero que en 1990 comenzó una etapa diferente de la anterior, en cuanto el desplome del mundo socialista dejó a todos los PP.CC. del mundo ante el desafío de definir su propia identidad y decidir si las condiciones de su existencia continuaban vigentes.
} 
cuarenta y cinco años -por tanto, jóvenes en comparación con la longevidad tan característica de los dirigentes comunistas- que habían ocupado responsabilidades intermedias en la década anterior y que en el contexto de la transición fueron promovidos a lugares de mayor visibilidad. Ya en los últimos años de la dictadura se habían producido cambios en la dirigencia partidaria por el fallecimiento de algunos de los principales dirigentes ${ }^{13}$. En 1980 murió el poderoso Secretario General, Gerónimo Arnedo Álvarez, quien fue reemplazado por Athos Fava, a su vez, reemplazado como Secretario de Organización por Jorge Pereyra, quien fue sustituido como Secretario General de la FJC por Patricio Echegaray. El fortalecimiento de este núcleo, sin embargo, terminó de consolidarse en noviembre de 1984 con la promoción de Echegaray a la dirección del periódico ¿Qué pasa? La jefatura en la redacción del "primer militante", como se suele denominar en la jerga leninista al periódico, significaba, en gran medida, el control sobre la línea del partido. Para esa tarea, contó con la ayuda de Alberto Nadra también promovido desde la Federación Juvenil Comunista (FJC) al partido. En la FJC, por su parte, se consolidó simultáneamente una dirección afín con este núcleo: Eduardo Sigal como Secretario General, Jorge Paveto como Secretario de Organización y Alejandro Mosquera a cargo de la secretaría de Propaganda. Que la propuesta de viraje naciera de un sector de la propia dirección del partido constituyó inicialmente un elemento de fortaleza para encarar el cambio, pero, a la vez, ponía un límite al carácter renovador. Como hemos dicho, ninguno era nuevo en el partido ni había alzado su voz crítica en el pasado ${ }^{14}$. Tampoco habían tenido que reinventarse por la fuerza de los hechos, como había ocurrido a los comunistas chilenos cuando se produjo la salida de su dirección al exilio ${ }^{15}$. ¿Qué era entonces lo que animaba a la renovación? La velocidad con la que fue encarado el cambio resulta sorprendente, en especial porque hasta finales de 1983 nada hacía pensar en que el viraje fuera inminente. En plena campaña electoral, por ejemplo, el partido publicó un libro, escrito por Arturo Lozza, sobre la gira de campaña de Rubens Íscaro por todo el país ${ }^{16}$. La crónica del viaje guardaba todos los clichés de la literatura militante tradicional. El dirigente esclarecido, humilde, que con sencillez se acerca al pueblo que no deja de mostrarle cariño y aprobación: ¿acaso algún militante comunista podía realmente anticipar que apenas tres años más tarde Íscaro sería expulsado? Es cierto que existían signos e disconformidad en la base que se habían manifestado en 1982, por ejemplo, con una silbatina en pleno acto en el Luna Park cuando se habló de "convergencia cívico militar", pero no llegaba a traducirse en planteos concretos y mucho menos de carácter global. Por lo contrario, durante 1982 y 1983 el partido había registrado un crecimiento en sus filas como resultado de la revitalización de todo el arco político y de las campañas de afiliaciones. Es probable, entonces, que el sector de la dirección que promovió el viraje haya percibido la necesidad de operar una revisión como un movimiento de anticipación, confiando en la capacidad para controlar la iniciativa.

\footnotetext{
13 De los miembros del CC elegido en 1974 murieron: Gerónimo Arnedo Alvarez (1980); Rodolfo Ghioldi; Héctor Agosti y Pedro Tadioli (1985).

14 Los dirigentes renovadores en su totalidad habían militado durante el periodo de la dictadura militar sin haber formulado críticas a la polémica línea de "convergencia cívico-militar".

15 Rolando Álvarez, Desde las sombras. Una historia de la clandestinidad comunista, Santiago de Chile, LOM, 2003.

16 Arturo Lozza, Viaje por el partido de los comunistas, Buenos Aires, Anteo, 1983.
} 
Recién en octubre de 1984 aparecieron los primeros gestos explícitos: la conformación de las "brigadas del café" para realizar tareas solidarias en Nicaragua y el ingreso del Che en la liturgia oficial ${ }^{17}$. La nueva radicalidad con la que los comunistas ingresaban en la etapa carecía de profundidad teórica, pero era muy expresiva en su estética y en el tipo de actividad que proponían. La proliferación de retratos del Che, de Evita y una actitud mucho más desenfadada hacia las novedades de la juventud venía a reemplazar el viejo estilo de militancia, identificada como pacata, excesivamente prosoviética y conservadora frente a las novedades de su tiempo ${ }^{18}$. Si tuviera que elegir una imagen para retratar esa nueva actitud, sin lugar a dudas, elegiría un afiche propagandístico de las brigadas de café en el que se ve a una mujer joven, portando un arma en la espalda, vestida en forma sencilla, con el pelo suelto, muy sonriente y amamantando a su bebé. La juventud como portadora de la renovación; la feminidad como símbolo del desafío al orden militar burgués reservado exclusivamente para los varones; el amamantamiento como reafirmación del ideal de "mujer nueva", una que compatibilizaba los roles maternales con los deberes del combate revolucionario; la sonrisa, la alegría del combate ${ }^{19}$. En suma, las armas de la revolución para construir al hombre y la mujer nueva, condensaron la propuesta más osada y original que formuló el comunismo en la primera etapa del "viraje". Se trataba de la búsqueda de una nueva identidad que tuviera la capacidad de recuperar elementos propios de la tradición partidaria con otros nuevos, en sintonía con lo que ocurría en todo el mundo comunista incluyendo el soviético que, por entonces, proponía la glásnost y la perestroica. Entonces, Cuba, Nicaragua, El Salvador y Chile proporcionaron los ejemplos del curso deseado. En Chile, también los jóvenes comunistas se habían reinventado en el fragor de la lucha contra el régimen de Pinochet, que, a diferencia de la última dictadura argentina, los tuvo como blanco principal del ataque. En la constitución del Frente Patriótico Manuel Rodríguez los comunistas chilenos habían tenido que lidiar con las críticas de dirigentes tradicionales que desde el llamado "Frente externo" discutían la orientación que iba tomando la acción política. Sin embargo, las condiciones políticas en Chile no eran las mismas que en Argentina donde el golpe de Estado era solo una hipótesis.

Otro elemento que ilustra bien el clima de "renovación" que dinamizaba a la militancia comunista es el vuelco que dio la actividad vinculada al frente de mujeres. Si bien la Unión de Mujeres Argentinas (UMA) siguió conformando un frente secundario y de poca o nula atención para el conjunto de la militancia, un límite que fue admitido en las propias resoluciones congresales, las militantes a cargo de dicha actividad fueron receptivas a los planteos que traía el feminismo. Aquí Nosotras, la revista de la UMA, se transformó íntegramente y comenzó a incluir temáticas como la violencia de género y la salud reproductiva, dos problemáticas que hasta entonces habían permanecido ausentes.

\footnotetext{
17 Para una historia pormenorizada de las brigadas del café, véase, Hellmund, op.cit.

18 Un trabajo interesante porque recupera el estado de ánimo de la militancia de aquel momento es el de Victoria Bona, "La Ferifiesta como binóculo de la reconversión del Partido Comunista de la Argentina en la posdictadura: por la paz, la democracia y el socialismo". En XVII Jornadas Interescuelas de los Departamentos de Historia, Universidad Nacional de Catamarca, 2, 3, 4 y 5 de octubre de 2019, mimeo.

19 "Allá vamos Nicaragua", Aquí y ahora la juventud. Recuperado del archivo policial de la ex-DIPBA, Mesa A, Legajo 5, Folio 193.
} 
En el movimiento de derechos humanos, en los sindicatos y en la política electoral, el PCA mostraba rasgos nuevos, herramientas con las que intervenía sin terminar de integrarlas en un planteo político coherente. En 1985 la propuesta de "viraje" tuvo su primera materialización en las Tesis del XVI Congreso. Este documento, el intento más serio y sistemático por darle consistencia y encuadrar la revisión en una dirección clara y definida, es una expresión de la intención de cambio y, también, de la ambigüedad teórica que explica los debates posteriores. Desde el punto de vista de los planteos más renovadores apareció una nueva actitud hacia la izquierda que se tradujo en la búsqueda de frentes electorales novedosos. Mirado de conjunto, tanto el Frente del Pueblo (1985), como el Frente Amplio de Liberación (1987) o Izquierda Unida (1989) fueron expresión de la voluntad de conformar alianzas con sectores claramente identificados con el socialismo ${ }^{20}$. Con todo, en el análisis del comunismo, la política de alianzas idealmente incluía también al peronismo de "izquierda" o peronismo "renovador". La interpretación del peronismo, sin embargo, siguió siendo problemática en gran medida porque su vida interna, sus movimientos y políticas de acuerdo seguían lógicas distintas a la de los partidos de izquierda, los cuales, para bien o para mal, se aúnan alrededor de programas y regulan su actividad por estatutos.

El otro núcleo que desde el punto de vista teórico debía reorientar la estrategia del partido era la revisión sobre la caracterización de la revolución, el reemplazo del "etapismo" y el objetivo de "revolución democrática" por el de "revolución socialista de liberación nacional y social". De acuerdo con la nueva formulación se trataba de corregir la caracterización de la estructura económica argentina. Se dejaba atrás la concepción de "insuficientemente capitalista" por otra que admitía el desarrollo pleno del capitalismo y la transformación de la burguesía nacional en socio menor del imperialismo y los monopolios. De allí, la recuperación del énfasis en la clase obrera que, luego de décadas, fue resituada como sujeto de la transformación revolucionaria. Sin embargo, como posteriormente varios militantes comenzaron a señalar, el carácter de la revisión era parcial dejando en pie otros elementos que reestablecían, por otro camino, la concepción tradicional. Quizás el principal problema radicaba en que el concepto de FLNS no era novedoso y, por tanto, contenía lo esencial del FDN. Como los propios renovadores argumentaron, el FLNS había sido la línea del partido desde el XII Congreso cuando la liberación nacional se pensaba como un campo de alianzas amplio que incluía a la burguesía nacional. En el fondo, puede pensarse que el problema de la revisión radicaba en su alcance y que, en ese punto, los revisionistas actuaron con excesiva cautela. La

\footnotetext{
${ }^{20}$ La década de 1980 suele ser recordada en la historiografía argentina como un momento de declive de los paradigmas revolucionarios y de desplazamiento hacia los horizontes democráticos o social-democráticos. Aunque comparada con la década anterior, es cierto que registró niveles menores de combatividad encauzada en proyectos revolucionarios, esta visión dominante subvalora el papel de las izquierdas nativas. Por caso, los partidos trotskistas crecieron exponencialmente produciendo una renovación en las referencias de la izquierda local. El Movimiento al Socialismo (MAS) y el Partido Obrero (PO) son ejemplos representativos de este proceso de reorganización del campo revolucionario. El MAS fue integrante del Frente del Pueblo y de Izquierda Unida. Llegó a tener más de 15000 militantes en sus filas y representaciones parlamentarias. En Argentina, la izquierda en su conjunto no se destacó nunca por su desempeño electoral, sino por su presencia en los movimientos sociales y su capacidad de incidir en conflictos que se dirimen fundamentalmente en el espacio público.
} 
ruptura con el etapismo los acercaba aceleradamente a los planteos clásicos de los partidos trotskistas, la caracterización sobre la incapacidad de la burguesía nativa para completar las "tareas" democráticas, incumplidas en los países de estructura dependiente, y la necesidad de una revolución permanente de aspiración socialista desde el inicio. Se trataba de una tradición tan abominada como temida por los comunistas que se separaba de una larga tradición partidaria en pos de la unidad amplia con los sectores "progresistas" o "democráticos". La revisión, al límite de desplazarse al campo del trotskismo, fue entonces atenuada con la rehabilitación del FLNS que no podía ser otra cosa que el regreso a las fuentes.

En resumen, asistimos al agotamiento de la etapa burguesa del desarrollo del país. Surge la necesidad objetiva de que se impulse y concrete la etapa obrera y popular: su contenido esencial es hacer la revolución popular, antioligárquica y antimperialisa hacia el socialismo ${ }^{21}$.

Esa ambigüedad, no pasó desapercibida para la militancia que, a medida que la crisis se agudizaba, comenzó a plantear por escrito las inconsistencias. Por ejemplo, así lo planteaba Saúl Blejman, miembro del Comité Provincial de Mendoza, en 1989:

[...] se argumenta contra la concepción anterior que consideraba al proceso revolucionario dividido en dos etapas: una primera revolución agraria, antimperialista y una segunda de carácter socialista, diferenciada de la anterior y separada en el tiempo. Se sostiene además que 'las transformaciones que propiciamos están enmarcadas en un único e ininterrumpido proceso revolucionario en el curso del cual se deberá ir dando cumplimiento a tareas de diversa índole en un curso que objetivamente tiende al socialismo'. Sin embargo, luego se afirma que 'dentro de las tareas de la primera época del estado revolucionario están aquellas de contenido democrático, agrario, antimonopolista, que no son tareas socialistas, pero que tendrán carácter anticapitalista y preparatorias de las tareas socialistas que deberán resolverse en un futuro cuyo momento de iniciación es inciertó. Con lo cual caemos de lleno en la teoría de las dos etapas 22 .

De cualquier manera, el debate teórico era apenas un aspecto del problema y poco antes de realizarse el XVI Congreso se generó el primer gran enfrentamiento interno. Promediando 1986 comenzó a prepararse el alejamiento de una primera tanda de dirigentes entre los que se encontraba Oscar Arévalo y Rubens Íscaro, dos de los miembros

\footnotetext{
21 Subrayado propio. Folleto, "La transformación leninista del partido", junio de 1987, p.5.

22 Saúl Blejman, "Respuesta al trabajo 'Argentina del Capitalismo al socialismo”", Cuaderno de economía, N², agosto de 1989, p. 23.
} 
más antiguos y poderosos del Comité Central. En las semanas previas al Congreso se realizaron encuentros regionales con el objetivo de elegir las nuevas conducciones y anticipar los debates. Ya entonces era un hecho que el Congreso se llevaría adelante en un clima de fuerte oposición cada vez más polarizada entre "veteranos reformistas" (así anatemizados por los opositores) y "jóvenes renovadores". Rubens Íscaro y Oscar Arévalo, fueron considerados los responsables por el reformismo del partido. Aunque Íscaro llegó a formar parte de los debates congresales, en los propios partes que el PC enviaba a la prensa se puede apreciar el tono acusatorio que tomaron contra estos antiguos jefes comunistas. En uno de estos partes se afirmaba:

[Rubens Íscaro] tuvo la posibilidad de explayarse largamente para expresar sus conocidas posiciones críticas al proyecto político. Sus palabras fueron fríamente recibidas por los congresales. A continuación hicieron uso de la palabra, refutando sus conceptos, el Dr. Alberto Barcesat (Director de la revista Nueva Era); Ballato (Secretario del PC de La Plata), quienes fueron ovacionados largamente con los delegados puestos de pie $^{23}$.

La sola contraposición entre "frialdad" y "ovación" dejaba constancia y preparaba el terreno para explicar la expulsión, la cual se concretaría en marzo de 1987, y presentarla como un acto unánime destinado a desterrar el estalinismo y el reformismo. En documentos internos posteriores, sin embargo, se reconocía que dichos dirigentes habían arrastrado consigo a varios militantes, también "veteranos", de distintas provincias, lo que matizaba la mentada soledad de los acusados. De hecho, durante 1987 Íscaro consiguió estructurar una corriente disidente, el "Ateneo Rodolfo Ghioldi" que llamaba a "salvar al partido de su disgregación" y acusaba al Comité Central renovado de haber "asaltado la dirección y conducido al partido hacia el guerrillerismo y la ultraizquierda"24. En sus palabras:

Asaltada la dirección y munidos de una heterodoxa orientación ultraizquierdista y guerrillerista, mezclada con posturas de derecha, se lanzaron a cortar cabezas, sembrando la arbitrariedad, estableciendo dentro del partido la ley de la selva y el canibalismo; y con soberbia teórica han lanzado a mejorar el marxismo-leninismo, uniendo los principios de éste con el trotskismo, el nacionalismo burgués y revolucionario, el ERP, los Montoneros y otras expresiones del ultraizquierdismo ${ }^{25}$.

Para los dirigentes separados el giro que había tomado la situación era en verdad sorprendente. En los primeros meses de 1984 habían apoyado el plan de reforma, en parte,

${ }^{23}$ Documentos del XVI Congreso. "Información para la prensa", 5 de noviembre de 1986.

24 Véase una reproducción parcial del documento en Clarín, "Llaman a formar una línea interna en el PC", 27 de octubre de 1987.

25 “Llaman a formar una línea interna en el PC", Clarín, 27 de octubre de 1987. 
porque eran conscientes de los factores que tornaban inevitable la adaptación a la nueva etapa. Sin embargo, pronto comenzó a quedar en claro que el núcleo reunido alrededor de Fava, Pereira y Echegaray tenía un proyecto propio y se encontraba embarcado en una senda de estudio que colocaba al partido en lugares muy distintos que los que había ocupado en el pasado. Antes de transformarse en lecturas obligadas, Shaffik Handal y el propio Che Guevara eran estudiados con una actitud casi herética. Cuando los dirigentes "veteranos" tomaron consciencia de hasta qué punto el viraje proponía una formulación política novedosa (que no seguía lineamientos internacionales tradicionales) ya era tarde para volver atrás, porque el conjunto del partido, en especial, hacia abajo y en la juventud, respetaba los nuevos liderazgos y tomaba con entusiasmo la invitación a formar parte de la (re)construcción.

\section{El viraje en su laberinto}

La segunda fase de la crisis difiere de la primera en cuanto se produjo dentro del propio grupo "renovador". Pone de relieve todos los límites e imprecisiones que había dejado la primera etapa con relación a dos núcleos de problemas: a) debates políticos no saldados completamente y b) malestar en torno de lo que se consideraba una forma burocrática de dirigir el partido perpetuada por los propios renovadores.

Se trata de una segunda etapa mucho más difícil de abordar y reconstruir empíricamente en la medida que los alineamientos políticos no provinieron necesariamente de "arriba" hacia "abajo", sino que brotaron en todas las direcciones. Regionales, provincias, tendencias constituidas de hecho dentro de regionales y también dentro del propio Comité Central, el partido comenzó a resquebrajarse y se produjeron reagrupamientos diversos. El peso de las individualidades, en este contexto, fue decisivo como factor explicativo poniendo de relieve que en política no siempre los alineamientos se deciden en función de la racionalidad teórica y que las trayectorias en común, la amistad y las lealtades personales tienen un gran poder de convocatoria. Conforme fue pasando el tiempo, los debates comenzaron a ser ganados por el faccionalismo. Las acusaciones cruzadas entre tendencias no formalizadas y nunca reconocidas como tales, pero conformadas en la realidad comenzaron a adquirir niveles de agresión y violencia tan altos que minaron la confianza mutua y la posibilidad de un intercambio político franco y camaraderil, dos condiciones sin las cuales no es posible construir un partido de izquierda. De acuerdo con el diccionario de la Real Academia Española (RAE), "camarada" significa: "persona que anda en compañía con otras, tratándose con amistad y confianza." En consecuencia, si en la comunidad de plebeyos desaparece la amistad y, sobre todo, la confianza, simplemente se extingue la organización. Para "conspirar" contra el Estado debe existir confianza al interior de los "conspiradores". Caso contrario, la unidad ya no es posible.

Desde luego, no era la primera vez que una crisis se procesaba con modos violentos y personales dentro del PCA. Sin embargo, merece una mínima reflexión: ocurre que la lucha por el poder dentro de los partidos revolucionarios rara vez se libra en torno de intereses económicos o alrededor de cargos públicos. Por lo general, el poder se corporiza en el orden simbólico. Ser respetado, llevar la razón, vencer en el debate son cualidades 
que denotan poder. Por lo contrario, no alcanzar el consenso, perder la admiración personal por parte de los dirigidos, son razones que con frecuencia conducen a guerras fratricidas dentro de las formaciones revolucionarias.

Volviendo a la descripción de la crisis, a nivel de la cúpula el grupo mayoritario tenía como principales referentes al Secretario General, Patricio, Echegaray, al Secretario de Organización Jorge Pereyra ${ }^{26}$ y al Presidente partidario (un cargo honorífico creado en abril de 1989), Athos Fava, quien representaba una especie de puente entre la vieja y la nueva dirigencia. Estos proponían una defensa cerrada de lo actuado desde el último Congreso y aspiraban a que el PCA se transformara en el eje de un frente de izquierda amplio. En la FJC los representantes más fieles de esta corriente eran Alejandro Mosquera y Claudia Korol. Fue este grupo el que mantuvo el control del partido una vez producida la ruptura al año siguiente.

La primera corriente disidente que surgió tenía como principales referentes a Francisco Álvarez, miembro de la Comisión Política, Jorge Prigoshin, Director del periódico partidario, Marcelo Arbit, responsable de derechos humanos y Enrique Dratman, Vicedirector del matutino Sur. Este grupo proponía una apertura del debate interno y consideraban necesario disolver el PCA en el marco de una nueva formación política que reuniese a las distintas expresiones de la izquierda, a sectores del peronismo y aun del radicalismo. La mayoría de ellos, en la década siguiente, se sumó a formaciones políticas de centro-izquierda, abandonando definitivamente los proyectos autodenominados revolucionarios.

Finalmente, la tercera línea hacía un fuerte hincapié en la democracia interna y denunciaba que el estalinismo no había muerto con el XVI Congreso. Esta tendencia estaba encabezada por el Secretario de Acción Política, Eduardo Sigal y por el Secretario de Propaganda, Ernesto Salgado. También se sumaba el responsable de la Regional Sur, Jorge Garra, quien había sido el jefe de las Brigadas del Café, y Miguel Ballato.

Una de las fuentes más interesantes para reconstruir los debates internos es la revista Ideología y Política que comenzó a publicarse en forma bimensual desde septiembre de 1987 con el objetivo de darle carnadura teórica al viraje. Como su nombre lo indicaba, la publicación aspiraba a profundizar los debates teóricos-ideológicos, no como simple ejercicio de especulación, sino como un resultado de la interacción con la praxis. Durante 1987 y 1988, en efecto, la revista publicó numerosas notas que por su densidad buscaban conformar un marco teórico para el viraje, limar inconsistencias y servir como herramienta de formación y nivelación de la militancia que, para ese entonces, dependiendo del momento en que hubiesen ingresado al partido, comportaban experiencias muy distintas. Sin embargo, a partir de 1989 y durante todo 1990 la revista perdió la homogeneidad de los primeros números y se transformó en una tribuna abierta de debate entre corrientes no formalizadas ${ }^{27}$. En un sentido, se trató de una experiencia inédita y muestra hasta qué punto el mandato democratizador del viraje, al menos como intención, había calado.

26 Debe decirse que el cargo de Secretario de Organización era muy importante. Aunque llevaba adelante tareas de poca exposición pública le permitía manejar las estructuras claves en el funcionamiento del PC y tener conocimiento de las finanzas, el patrimonio y la seguridad interna.

27 El PCA es un partido centralizado y no aprueba en sus estatutos la constitución de tendencias o fracciones internas. 
Ideología y Política era dirigida por Ernesto Salgado, representante de una de las corrientes minoritarias, pero en el consejo de redacción había representantes de todas las posiciones: Claudia Korol, Marcelo Arbit y Jorge Garra, por mencionar un miembro por cada tendencia.

Sin embargo, en los organismos cotidianos y a medida que se acercaba la fecha para la realización del XVII Congreso, pactado para fines de 1990, los debates fueron cada vez más virulentos. Sin dudas, las graves acusaciones mutuas, que iban desde la "traición" hasta las sospechas por el supuesto uso indebido de los fondos partidarios, fueron achicando el margen de posibilidad de arribar a un acuerdo. El salto de lo político a lo personal imposibilitó cualquier posibilidad de acuerdo tornando inviable la convivencia.

En las vísperas del XVII Congreso, todas las tendencias intentaban imponer su propio criterio para la elección de delegados sobre un total de 12.000 militantes (según cifras oficiales). Cada tendencia, a su vez, era poderosa en diferentes sectores del partido y tenía capacidad de traccionar a la militancia, la cual en muchas ocasiones participó del debate respaldando a una u otra corriente y en otras fue apenas una voz solitaria y confusa que no alcanzaba a comprender la dimensión de lo que estaba sucediendo. Fue gracias a las quejas de la militancia que seguía el debate más por los medios nacionales que por las comunicaciones del partido, que en 1990 comenzó a circular un boletín interno denominado "opiniones con nombre propio" con el fin de democratizar la discusión. Sin embargo, sería el preludio del fin, una catarsis colectiva destinada a sacar la única conclusión posible: cada quien debía seguir su camino.

\section{El régimen interno}

Llegados a este punto del artículo, quisiera detenerme en un elemento que considero central para comprender la caladura de la crisis: el intento de poner fin al personalismo y a la burocratización del partido, dos fenómenos entrelazados, pero no idénticos.

Al respecto de este último punto mi trabajo dialoga con una historiografía más amplia. En particular con el trabajo del historiador chileno Rolando Álvarez que, en los últimos años, ha trabajado sobre la crisis del PC de Chile en la posdictadura (1990). En la visión de Álvarez, la existencia de divergencias profundas que coexisten y bregan por orientar el partido, desarma una idea muy arraigada en torno de los PPCC que, tomando como modelo los partidos en tiempos del estalinismo, tendió a canonizar una imagen poco proclive a visibilizar las porosidades, especificidades y dinámicas propias de cada formación en distintos momentos. Ahora bien, aunque personalmente acuerdo con la inviabilidad de las representaciones de los partidos como totales o monolíticas, creo que el monolitismo fue un elemento importante como aspiración. En el PCA, que es el caso que analizo aquí, antes de caer en descrédito, el monolitismo fue un horizonte deseado porque se veía en él un vehículo necesario para construir una organización poderosa, capaz de "golpear como un solo puño"; una aspiración, por otro lado, no privativa del comunismo y que podríamos atribuir también a otras tradiciones de izquierda dentro del leninismo. Como he intentado mostrar en otras ocasiones, hacia los años 1970 todavía estaba extendida entre los militantes la idea de que la pertenencia al PCA los hacía miembros de 
una maquinaria vigorosa, aceitada y con lazos en todo el mundo. Incluso, esa misma autorepresentación había cumplido un papel en la recuperación del activo militante durante la década de 1970. Entonces, convertida en virtud o en defecto, pareciera ser que el plus del PCA con relación al resto de la izquierda estaba asociado con el tamaño de su aparato, sus recursos y la capacidad para intervenir en los frentes más diversos. Ese conjunto de representaciones, muchas veces alimentaba la "fe ciega" en la dirección basada no tanto en la idea de que los dirigentes eran mentes esclarecidas como en la creencia de que disponían de información. Entonces, a pesar de que la sociedad de los años 1970 era mucho más democrática en comparación con la de los años 1930, cuando el autoritarismo tenía gran legitimidad, cierto es que, en la cultura interna, la disciplina y la homogeneidad de ideas gozaba de buena salud. Incluso la compartimentación extrema, un elemento clave de la burocratización, antes de ser criticada como una realidad que operaba contra la democracia interna, fue justificada como un recurso necesario para defender a la organización de la persecución estatal, un argumento que ciertamente no puede pasarse por alto. Sin embargo, en base a esa creencia también fue justificada la política durante la última dictadura. Como he reconstruido en mi libro sobre esta cuestión, muchos militantes fueron leales a la línea porque confiaban en la información que tenía la dirección que, a diferencia suya, recibía reportes de todo el país. Para 1983 esa confianza comenzó a erosionarse, aunque las críticas no se ventilaran públicamente. Lo primero que ocurrió, entonces, fue el reconocimiento en el marco del XVI Congreso de que el problema existía y se manifestó como la necesidad de poner fin al "personalismo" y las prácticas del "mando y obedezco".

El personalismo, como fenómeno político, no es exclusivo de un tipo de partido. En el PCA tuvo sus formas históricas concretas mediante una pedagogía de la obsecuencia con la dirección, y el culto de la personalidad. El análisis de estos dos elementos excede las posibilidades de este trabajo, pero vale la pena estudiarlos en su especificidad. Puede pensarse que la muerte de Codovilla atenuó el personalismo. Sin embargo, quedaban otros líderes históricos que eran tratados con la misma pleitesía. El XVI Congreso buscó poner fin a ese fenómeno separando a dos de los principales dirigentes aún vivos. Aunque los lugares dejados vacantes fueron ocupados por renovadores que ya gozaban de autoridad política entre la militancia, ninguno podía atribuirse el poder en exclusiva. Existía el desafío, entonces, de construir una dirección colectiva.

El burocratismo interno, en cambio, fue un elemento mucho más conflictivo por cuanto suponía revisar una forma de construcción partidaria muy arraigada en el tiempo.

La desviación reformista se tradujo en la vida interna del partido [...] en la vigencia del ordeno y mando, del principio de autoridad e infalibilidad de los dirigentes. A su vez, la línea y su elaboración no eran patrimonio del conjunto del partido [...] y como expresión del divorcio entre la teoría y la práctica, el trabajo ideológico quedó recluido a un núcleo estrecho que elaboraba mientras el resto eran ejecutores, muchas veces con criterio administrativista. [...] Este abandono del leninismo se tradujo también en un deterioro moral y 
la auténtica disciplina revolucionaria fue reemplazada por el autoritarismo y la sumisión ${ }^{28}$.

Puede decirse que prácticamente todos los partidos revolucionarios lidian con la tensión entre la necesidad de democratizar la palabra (como precondición para la elaboración política atenta de los fenómenos que ocurren en el seno de la población) y la necesidad de definir una línea, construir lealtad con las elecciones de la mayoría y ciertos niveles de disciplina, aun en el desacuerdo. Casi todos los partidos tienen, en algún momento de su vida, dificultades para armonizar mandatos que, en esencia, son contradictorios. El problema de los partidos revolucionarios, como ha sido profusamente teorizado por los clásicos, consiste en que la lucha por el derrocamiento del Estado capitalista no puede ser exitosa sin disciplina ${ }^{29}$. Por definición son partidos que conspiran contra el orden instituido y por tanto precisan de dosis de "militarización" interna y de cuadros profesionalizados para alcanzar el éxito. Para conciliar elementos en permanente tensión los partidos leninistas proclamaron el centralismo democrático. Sin embargo, en la experiencia histórica real del PCA, el mandato de la disciplina interna conjugada con la compartimentación de funciones y de la información, que se sumaba el personalismo, fueron elementos que prevalecieron sobre la democracia interna, reemplazando el centralismo democrático por el centralismo burocrático ${ }^{30}$. Si esa forma de funcionamiento partidario tenía una larga historia, durante la última dictadura militar los espacios para el debate interno se estrecharon al mínimo por las propias condiciones políticas impuestas por la suspensión de la actividad política y la extensión del terror. Es decir, que al comenzar los años 1980 era prácticamente nula la democracia interna. Para entonces, el PCA se caracterizaba por encarnar una enorme burocracia, en el sentido más literal del término, es decir, una formación de hombres y mujeres que ejercen dentro de la estructura una función específica, técnica y la llevan adelante con eficiencia y respondiendo a un orden jerárquico. Otra característica de la burocracia es la de poseer un saber que la torna necesaria para el funcionamiento del conjunto. Dentro del PCA esta situación se plasmaba en un tipo de división de tareas compartimentada que favorecía la especialización de los militantes en ciertas tareas en desmedro de otras, en el acceso diferencial a la información y en el ejercicio de la militancia de manera profesional y rentada. Desarmar esa realidad, desde luego, no dependía de una mera proclamación. Exigía tomar decisiones que afectaban la reproducción económica de muchas personas e incluso comprometían al patrimonio del partido. La cuestión del sostén económico de la militancia también constituye un problema nodal en los partidos políticos. Como el desarrollo de ciertas tareas es incompatible con una segunda jornada laboral la dedicación exclusiva de muchos cuadros aparece como una necesidad de primer orden. Sin embargo, esa situación perpetuada en el largo plazo constituye un síntoma de burocratización difícil de contrarrestar. El efecto más directo es que la reproducción material de las personas pasa a depender de la organización afectando, potencialmente, la capacidad de ejercer una

28 Informe del Comité Central al XVI Congreso, 4 de noviembre de 1986, Editorial Anteo, p. 30.

${ }^{29}$ Es probablemente el ¿Qué hacer? de Lenin, la obra que más emblemática que analiza la importancia de organizar un partido de cuadros profesionalizados.

30 Anteriormente hemos desarrollado el significado de estos conceptos a la luz de la obra de Gramsci. 
actitud crítica respecto de las decisiones que se toman en el orden superior. Es decir, el sostenimiento económico de la militancia tiende, al menos con gran probabilidad, a desarrollar una actitud conservadora por parte de esos cuadros para quienes la autonomía crítica podría significar la pérdida del empleo. La segunda consecuencia, que se desprende de lo anterior, es que los cuadros rentados, en tanto funcionarios del partido, renuncian a trabajar en otros puestos perdiendo contacto con el mercado laboral y sin poder acreditar experiencia en caso de tener que conseguir otro modo de sustento. En los partidos capitalistas esta situación también está presente, pero suele resolverse con la rotación de los cuadros intermedios entre diferentes partidos o alianzas electorales. Diputados, intendentes, concejales, asesores que rotan por diferentes formaciones del arco político buscando sostenerse dentro la "carrera" política. En los partidos de izquierda esta situación se vivencia de un modo diferente, en gran medida porque el acceso a cargos de gobierno es marginal y circunstancial. El funcionario político en los partidos de izquierda es imaginado como un conspirador profesional y su dedicación exclusiva está al servicio de la organización revolucionaria de las masas y no de la perpetuación del régimen capitalista. En el contexto de la crisis posterior al XVI Congreso esa situación significó la pérdida de rentas para muchos militantes que debieron afrontar la situación de reinventarse laboralmente. Por caso, un militante, a quien entrevisté en varias ocasiones entre el 2009 y el 2011 para mi tesis doctoral, me contó con pesar cómo al renunciar al partido había tenido que vender llaveros en los colectivos para poder sobrevivir. Esa situación, ilustra bien una sub-trama de la crisis y permite entender que las motivaciones para alinearse en uno $u$ otro bando podían ser múltiples ${ }^{31}$.

Llegado a este punto del artículo quisiera plantear cuál es mi hipótesis respecto de la crisis, al menos con relación al funcionamiento interno. Mi interpretación es que la crítica al centralismo burocrático propiciada desde "arriba" por los promotores del "viraje" generó un efecto búmeran en cuanto contribuyó a quebrar la legitimidad de los principios de obediencia. Desde entonces, la efectiva democratización de la palabra se volvió contra los propios reformadores que debieron afrontar focos de disidencia que emergían en todas las direcciones y escalas del partido. En este sentido, pienso que todas las tendencias que cristalizaron a finales de los años 1980 son hijas legítimas el "viraje" del XVI Congreso, en el sentido de que son herederas del proceso que habilitó el debate y la lucha contra el burocratismo. De igual modo, la extinción (biológica o por expulsión) de una parte de la dirección histórica, efectivamente atenuó los personalismos entendido como la obsecuencia con individualidades que se reservan el derecho de arbitrar, vetar y decidir a su antojo. Sin embargo, la desaparición de dirigentes con capacidad de alinear tras de sí al conjunto del partido fue reemplazado por la emergencia de varios liderazgos que competían entre sí, sin lograr prevalecer completamente. A largo plazo, el procesamiento de esa crisis implicó la ruptura y el desgajamiento en múltiples agrupaciones.

\footnotetext{
31 La persona en cuestión era militante de Quilmes, un barrio del conurbano bonaerense sur. Desde su juventud había estado vinculado al partido y no conocía otra forma de vida social, laboral e incluso afectiva que aquella que se desenvolvía en las redes comunistas.
} 
Natalia Casola, Cuando se quebró el muro. Algunas notas acerca de la crisis en el Partido Comunista argentino durante los años 1980, Izquierdas, 49, 2020:1752-1771

\section{Algunas consideraciones finales}

A comienzos de los años 1990 el PCA debió asumir el desafío de encarar la intervención pública con un activo militante disminuido. Y aun debió afrontar nuevos alejamientos. Como hemos visto en este artículo, el clima de época atravesado por la caída del Muro y desplome sin solución del mundo soviético constituyeron un golpe enorme para el conjunto de la izquierda revolucionaria en el mundo, incluso para aquella que era crítica del socialismo soviético. En los PPCC ese golpe se sintió aún más fuerte, en cuanto desaparecía la que había sido su principal referencia mundial por décadas. La crisis dentro del PCA acusó recibo de ese contexto más general. Sin embargo, las razones fundamentales eran endógenas.

En la memoria oficial del PCA, sostenida por el grupo dirigente y la militancia que continuó dentro del partido en la década siguiente, los años 1980 son recordados como los pusieron fin al reformismo político y el burocratismo interno para producir una transformación profunda, un "viraje revolucionario". En esa narrativa la existencia de la crisis no es negada (no podrían) pero se la explica como el precio que debió pagarse para producir la transformación interna que dio lugar a la emergencia de una "nueva" generación "hija" del viraje. En mi visión, sin embargo, ser "hijo" o "hija" del "viraje" significó muchas cosas y fue justamente esa posibilidad de darle múltiples sentidos lo que explica el curso que tomaron las cosas a partir de 1986.

En este artículo he intentado analizar la dinámica de la crisis considerando dos aspectos nodales: el debate programático y la crisis de régimen interno. Con relación al primer problema, destaqué que el XVI Congreso propuso nuevas formulaciones y, con mayor o menor éxito, consiguió imponer puntos de vista novedosos o llegó a las mismas interpretaciones del pasado, por otra vía. Sin embargo, los debates políticos no saldados completamente comenzaron a pesar a partir de 1987 cuando empezó a emerger la consciencia de que no todos interpretaban el viraje en el mismo sentido. Este problema se entrelazó con el segundo y muchas veces sirvió para esconder o disimular las rivalidades por el poder dentro del aparato partidario. Al menos fue así en los primeros tiempos. Hacia fines de 1990 el desplazamiento hacia las formas de enfrentamiento faccioso enterró la posibilidad de alcanzar un acuerdo. La crisis tocaba fondo y la ruptura se tornó una realidad.

Con este trabajo no pretendo dar por agotado el tema. Por lo contrario, considero que existe una agenda de problemas que merecen consideración específica. Algunos los he mencionado: el peso de la tradición personalista construida en base a una pedagogía del culto a la personalidad y junto con ello, el análisis de las características que tuvieron algunos dirigentes como Patricio Echegaray para conseguir sostenerse en el tiempo al punto de personificar el mismo la "renovación"; el problema de las tensiones inherentes a la necesidad de conjugar disciplina y democracia; la incidencia de los cambios culturales en las dinámicas de los partidos con estructuras cristalizadas; la deslegitimación más general del autoritarismo y, por tanto, del monolitismo como modelo de partido; los efectos involuntarios de la apertura política, aun en condiciones en las que se suponía que existía control por parte de la dirección. Cada uno de estos aspectos amerita mayor investigación y reflexión. En conclusión, avanzar hacia el estudio profundo de los años 
1980 por parte de los historiadores del comunismo permitirá sentar las bases para la comprensión de su derrotero posterior e, incluso, de las condiciones de su reconstrucción en los nuevos escenarios.

\section{Bibliografía}

Álvarez Rolando, Desde las sombras. Una historia de la clandestinidad comunista, Santiago de Chile, LOM, 2003.

“¿Herejes y renegados?: la diáspora de la disidencia comunista chilena

(1989-1994)", VIII Jornadas de Trabajo en Historia Reciente, Facultad de Humanidades, Universidad Nacional de Rosario, 9 al 12 de agosto de 2016.

"Hijos e hijas de la Rebelión. El Partido Comunista de Chile en la postdictadura (1990-2000)", Workshop organizado por la Red Iberoamericana de Estudios sobre comunismo, RIECOM, Buenos Aires, 12 y 13 de junio de 2019.

Anderson Perry, "La historia de los partidos comunistas", en Raphael Samuel (Ed.), Historia popular y teoría socialista, Barcelona, Editorial Crítica, 1984.

Bona Victoria, "La Ferifiesta como binóculo de la reconversión del Partido Comunista de la Argentina en la posdictadura: por la paz, la democracia y el socialismo". En XVII Jornadas Interescuelas de los Departamentos de Historia, Universidad Nacional de Catamarca, 2, 3, 4 y 5 de octubre de 2019, mimeo.

Browarnik Graciela, "Sangre roja. Un estudio acerca de la transmisión de la tradición del Partido Comunista argentino durante la última dictadura militar y la posdictadura", Testimonios, N¹, Buenos Aires, 2009, pp. 20-35;

Casola Natalia, El PC argentino y la dictadura militar. Militancia, estrategia política y represión estatal, Buenos Aires, Imago Mundi, 2015.

Cernadas Jorge, Tarcus Horacio y Pittaluga Roberto, “La historiografía sobre el Partido Comunista de la Argentina: un estado de la cuestión”, El Rodaballo, n 8: Buenos Aires, 1998.

Fernández Hellmund Paula Daniela, Nicaragua debe sobrevivir. La solidaridad de la militancia comunista argentina con la Revolución Sandinista (1979-1990), Buenos Aires, Imago Mundi, 2015.

Gilbert Isidoro, La Fede, Buenos Aires, Sudamericana, 2009.

Antonio, Gramsci, Notas sobre Maquiavelo, Buenos Aires, Nueva Visión, 1984

Nadra Alberto, Secretos en rojo, un militante entre dos siglos, Buenos Aires, Corregidor, 2012.

Sigal Jorge, El día que maté a mi padre, confesiones de un ex comunista, Buenos Aires, Sudamericana, 2006.

Documentos citados

"Allá vamos Nicaragua", Aquí y ahora la juventud. Recuperado del archivo policial de la ex-DIPBA, Mesa A, Legajo 5, Folio 193.

Blejman Saúl, "Respuesta al trabajo 'Argentina del Capitalismo al socialismo'”, Cuaderno de economía, N², agosto de 1989, p. 23. 
Bovin Alexander, "La Perestroica y los destinos del socialismo", Ideología y Política, Año 1, Nº1, agosto-septiembre de 1987.

Brabivker Mario José, "Lenin sin dogmas", en Ideología y Política, Año 1, N³, diciembre de 1987.

Documentos del XVI Congreso. "Información para la prensa”, 5 de noviembre de 1986.

García Barceló Abel, “¿Puede haber revolución en la revolución?”, en Ideología y Política, Año 1, N³, diciembre de 1987.

Giúdice Ernesto, Carta a mis camaradas, Buenos Aires, Granica, 1974.

Folleto, "La transformación leninista del partido", junio de 1987.

Informe del Comité Central al XVI Congreso, 4 de noviembre de 1986, Editorial Anteo, p. 30.

"Llaman a formar una línea interna en el PC", Clarín, 27 de octubre de 1987.

Lozza Arturo, Viaje por el partido de los comunistas, Buenos Aires, Anteo, 1983.

Periódicos y revistas consultadas

Ideología y Política, (16 números) Desde agosto 1987- mayo 1990

¿Qué pasa?, Semanario del Partido Comunista (1982-1987)

Aquí Nosotras, Revista de la Unión de Mujeres Argentinas (1983-1991) 